\title{
Ten-year follow-up of coronary revascularization in a pediatric case with homozygous familial hypercholesterolemia
}

\author{
Mehmet Kerem Oral, Bülent Polat, Mehmet Ezelsoy
}

Department of Cardiovascular Surgery, İstanbul Florence Nightingale Hospital, İstanbul, Turkey

Received: August 23, 2016 Accepted: November 20, 2016 Published online: January 11, 2017

\section{ABSTRACT}

Homozygous familial hypercholesterolemia can cause coronary artery stenosis during childhood. Herein, we report a six-year-old boy who underwent coronary artery bypass grafting and liver transplantation at the same clinic four months later.

Keywords: Coronary artery bypass grafting, Familial hypercholesterolemia; liver transplantation; pediatric coronary bypass.

Homozygous familial hypercholesterolemia $(\mathrm{HFH})$ is a rare, but a serious genetic disorder with a mutation in the low-density lipoprotein (LDL) receptor. ${ }^{[1]}$ It is characterized by severely elevated serum LDL levels and cutaneous, tendinous xanthomas, and an increased risk of premature coronary artery disease (CAD), which may necessitate coronary artery bypass grafting (CABG) in children.

Herein, we report a six-year-old boy who underwent $\mathrm{CABG}$ and liver transplantation at the same clinic four months later.

\section{CASE REPORT}

A six-year-old boy was admitted to our clinic with a history of chest pain in May 2006. He was diagnosed with HFH six months ago, and was scheduled for liver transplantation. He received medical therapy including atorvastatin $40 \mathrm{mg}$ daily and ezetimibe $10 \mathrm{mg}$ daily. With the treatment, total cholesterol was $768 \mathrm{mg} / \mathrm{dL}$, LDL cholesterol $679 \mathrm{mg} / \mathrm{dL}$, high-density lipoprotein (HDL) cholesterol $24 \mathrm{mg} / \mathrm{dL}$, and triglycerides $85 \mathrm{mg} / \mathrm{dL}$ in the blood tests. Other parameters were within normal ranges. In the preoperative period, stable angina was detected and coronary angiography was performed. There was severe stenosis at the proximal left main coronary artery (LMCA) (90\%) and multiple mild stenotic lesions at the other coronary arteries (Figure 1). Thallium myocardial scintigraphy was performed and myocardial ischemia was seen only at the left anterior location. Echocardiography showed normal ejection fraction with $65 \%$ and aortic valve and aortic wall thickening without gradient. Carotid arteries were examined with Doppler ultrasound, and there were no evidence of stenosis, despite small atheromatous plaque formations.

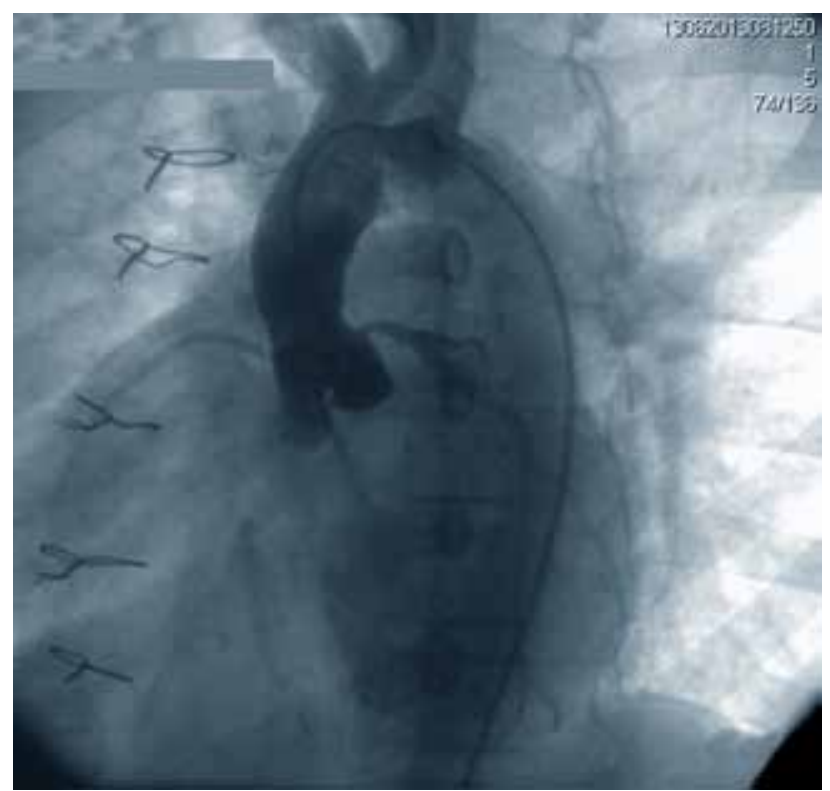

Figure 1. Preoperative aortography.

Corresponding author: Mehmet Kerem Oral, MD. Florence Nightingale Hastanesi Kalp ve Damar Cerrahisi Kliniği, 34381 Şişli, İstanbul, Turkey. Tel: +90 532 - 6834388 e-mail: keremoral@gmail.com 
Myocardial revascularization was indicated. The patient was scheduled for CABG. A written informed consent was obtained from his parents. After general anesthesia and via a midline incision, the chest was opened and the left internal mammary artery (LIMA) was harvested. Using on-pump technique, we bypassed the LAD with LIMA. Due to the small size of the thorax and the presence of ischemia only at the anterior part of the myocardium, a bypass to circumflex artery was not performed. Surgery was completed without any complication.

The postoperative course in the intensive care unit was uneventfully and he was discharged home on Day 5. He was prescribed acetylsalicylic acid $80 \mathrm{mg}$ daily, atorvastatin $40 \mathrm{mg}$ daily, and ezetimibe $10 \mathrm{mg}$ daily with diet modification. The cardiac status was checked for the transplantation surgery one month after CABG. We performed a stress test and found no ischemic changes. At three months of follow-up, total cholesterol was $868 \mathrm{mg} / \mathrm{dL}$, HDL cholesterol $29 \mathrm{mg} / \mathrm{dL}$, LDL cholesterol $810 \mathrm{mg} / \mathrm{dL}$, and triglycerides $121 \mathrm{mg} / \mathrm{dL}$. His chest pain resolved.

The patient was, then, referred to the liver transplantation unit three months after the operation. The liver transplantation was done at four months with living donor transplantation technique.

Ten days after transplantation surgery, total cholesterol was $215 \mathrm{mg} / \mathrm{dL}$, HDL cholesterol

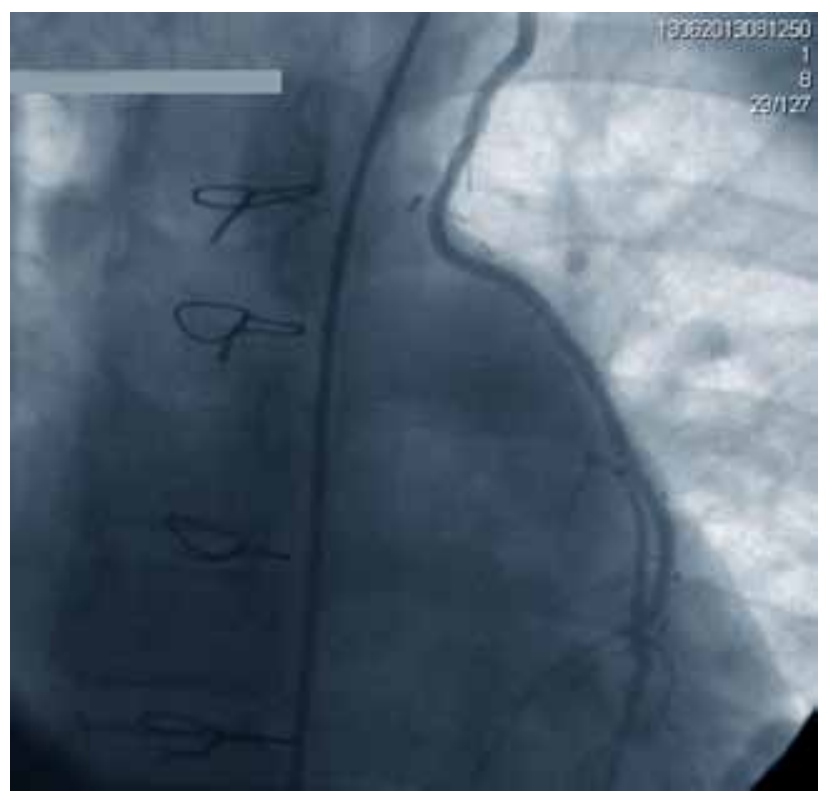

Figure 2. Postoperative control angiography.
$20 \mathrm{mg} / \mathrm{dL}$, LDL cholesterol $152 \mathrm{mg} / \mathrm{dL}$, and triglycerides $214 \mathrm{mg} / \mathrm{dL}$. In the first year of follow-up, xanthomas regressed.

After the transplantation, his serum cholesterol level was $150 \mathrm{mg} / \mathrm{dL}$, and he did not suffer from any complaint related to cardiac ischemia.

Based on his outpatient follow-up results, the patient was stable. Treadmill tests were performed with 12 month intervals to evaluate the ischemia of the myocardium; however, there was no evidence of ischemia. In June 2013, we performed coronary angiography to control the graft (Figure 2). The LIMA-to-LAD anastomosis was stable without any evidence of a new cardiac disease. In addition, there were intimal thickening at the abdominal aorta and its main branches which did not cause any clinical complaint (Figure 3).

\section{DISCUSSION}

Homozygous familial hypercholesterolemia is an autosomal dominant disorder which is associated with accelerated atherosclerosis and the development of multiple tendon xanthomas. ${ }^{[1]}$ The primary challenge is LDL receptor disorder in the liver that is why liver transplantation is indicated, if medical therapy fails to lower the blood lipid levels. Patients with $\mathrm{HFH}$ carries out a high risk to develop CAD usually in the

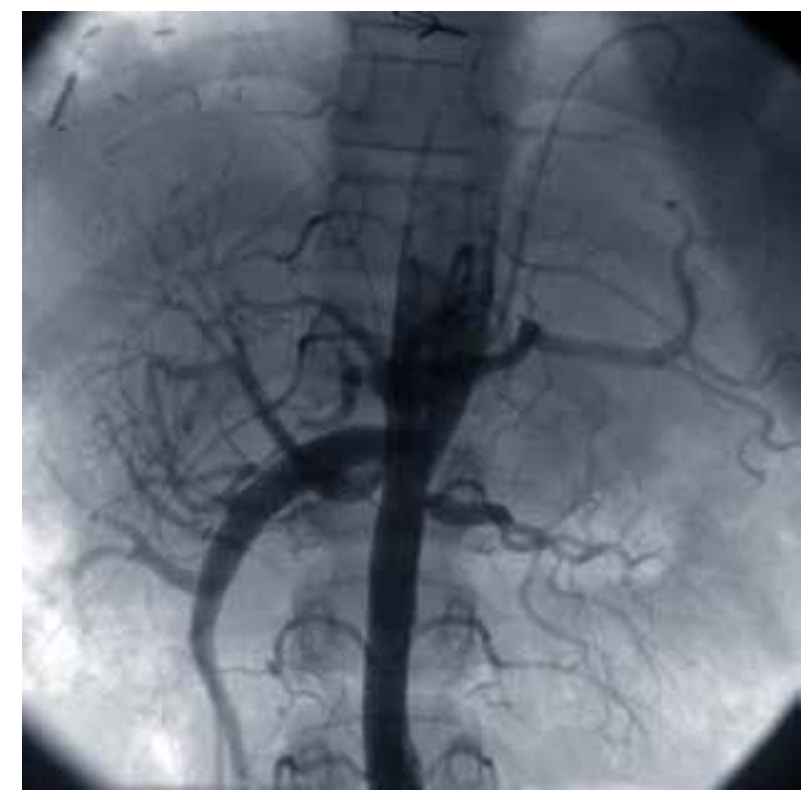

Figure 3. Abdominal aortography. 
second or third decades of life; however, very early onset of CAD in childhood has been also reported in the literature. ${ }^{[1]}$ The youngest child reported for CABG with familial hypercholesterolemia was a seven-year-old boy ${ }^{[2]}$ However, our case is nominated to be the youngest patient for CABG surgery in the literature.

Recently, the use of arterial conduits for coronary problems in infants and children has been widely adopted with excellent long-term patency and growth in children. ${ }^{[3,4]}$ Variations in the adaptation to growth of children have been shown between the arterial and venous grafts with thoracic artery growing in a proportion to somatic growth, while saphenous vein grafts tend to course in a more linear way without any increase in the length or diameter ${ }^{[5-7]}$ In our case, the choice of LIMA depended on its growth potential. However, the small size of the thorax, LIMA and coronary arteries makes it difficult to position the thorax, to harvest LIMA, and to anastomose it to a small coronary artery. For multiple coronary artery anastomoses, the right internal mammary artery can be also used either as T-graft or as separately.

Very high blood LDL levels should be controlled in patients with $\mathrm{HFH}$ via drugs, plasmapheresis, or liver transplantation. ${ }^{[9]}$ In patients refractory to medical treatments, transplantation is the most effective and most durable way to control LDL levels and its complications, ${ }^{[10]}$ as the problem is disorder of LDL receptors at the liver. A new liver with a normal working LDL receptor allows the patient to manipulate the blood LDL level.

The first description of the living-related liver transplantation procedure procured from a living donor (the mother) and transplanted in a child dates back to $1988 .{ }^{[8,9]}$ Living-related liver transplants soon came to account for a substantial number of pediatric cases performed in many centers throughout the world, and the only possibility for liver transplants in countries, where cadaveric organ procurement was not allowed until a few years ago.

In our case, the absence of the lateral wall ischemia of the myocardium gave us the courage not to do bypass to the circumflex artery, since we did not prefer using neither a venous graft nor a right internal mammary artery graft at such a young case for the stretching potential of these grafts as the child grows up. On the other hand, there were soft atheromatous plaques at the aorta which may cause distally embolism. We cannulated aorta, as it would be difficulty to do bypass surgery with offpump techniques in a child; however, we avoided an additional manipulation with proximal anastomosis which we did not consider that the patient needed it, due to the lack of the lateral wall ischemia.

In conclusion, coronary revascularization in childhood is a rare procedure. The patients with homozygous familial hypercholesterolemia must be followed closely for the development of coronary atherosclerosis particularly in patients scheduled for liver transplantation. The surgical results for cardiac revascularization are usually satisfactory in ischemic patients. However, long-term survival of the patients depends on strictly controlling lipid levels, due to the ongoing nature of the disease. Our case is the youngest patient with homozygous familial hypercholesterolemia undergoing coronary artery bypass grafting procedure with the longest follow-up.

\section{Declaration of conflicting interests}

The authors declared no conflicts of interest with respect to the authorship and/or publication of this article.

\section{Funding}

The authors received no financial support for the research and/or authorship of this article.

\section{REFERENCES}

1. Nemati MH. Coronary revascularization in a child with homozygous familial hypercholesterolemia. Interact Cardiovasc Thorac Surg 2010;10:131-2.

2. Ersoy U, Güvener M. Coronary revascularization in seven-year-old boy with homozygous familial hypercholesterolaemia. Acta Paediatr 2000;89:1501-2.

3. Mavroudis C, Backer CL, Muster AJ, Pahl E, Sanders $\mathrm{JH}$, Zales VR, et al. Expanding indications for pediatric coronary artery bypass. J Thorac Cardiovasc Surg 1996;111:181-9.

4. Kameda Y, Kitamura S, Taniguchi S, Kawata T, Mizuguchi $\mathrm{K}$, Nishioka H, et al. Differences in adaptation to growth of children between internal thoracic artery and saphenous vein coronary bypass grafts. J Cardiovasc Surg (Torino) 2001;42:9-16.

5. El-Khouri HM, Danilowicz DA, Slovis AJ, Colvin SB, Artman M. Saphenous vein graft growth 13 years after coronary bypass in a child with Kawasaki disease. Ann Thorac Surg 1998;65:1127-30.

6. Raia S, Nery JR, Mies S. Liver transplantation from live donors. Lancet 1989;2:497.

7. Strong RW, Lynch SV, Ong TH, Matsunami H, Koido Y, Balderson GA. Successful liver transplantation from a living donor to her son. N Engl J Med 1990;322:1505-7. 
8. Tunçer E, Başaran M, Çine N, Tüzün B, Ceyran H. Coronary revascularization in a 13 year old patient with homozygous familial hypercholesterolemia. Turk Gogus Kalp Dama 2014;22:168-70.

9. Kawasuji M, Sakakibara N, Fujii S, Yasuda T, Watanabe Y. Coronary artery bypass surgery with arterial grafts in familial hypercholesterolemia. J Thorac Cardiovasc Surg 2000;119:1008-13.

10. Küçükkartallar T, Yankol Y, Kanmaz T, Topaloğlu S, Acarli $\mathrm{K}$, Kalayoglu M. Liver transplantation as a treatment option for three siblings with homozygous familial hypercholesterolemia. Pediatr Transplant 2011;15:281-4. 